\title{
Performance of Clay Wood Cook Stove: An Analysis of Cost and Fuel Savings
}

\author{
A. Kuhe ${ }^{*}$, H.A. lortyer and A. lortsor
}

Department of Mechanical Engineeering, University of Agriculture, P.M.B. 2373 Maurdi, Nigeria

\begin{abstract}
The assessment of cooking energy cost and efficiency of improved woodfuel clay cookstoves in Nigeria have been considered in this study. Two improved wood burning clay cookstove models were compared to the 3-stone fire stove using the water boiling test and controlled cooking test. The following parameters: specific fuel consumption (SFC), thermal efficiency, ebulution time and cooking energy cost were considere as key indicators for comparison. The results show that the fire power for the cold starts phases were $7.72 \mathrm{KW}, 8.59 \mathrm{KW}$ and $9.78 \mathrm{KW}$ for the stove with grate, modified stove without grate and the 3-stone open fire (TFS) respectively. The thermal efficiencies ranges between 19-35\%, 13.8$26.8 \%$ and $11.7-22.8 \%$ for the cold start, hot start and simmer phases for mud stove with grate (MSWG), mud stove no grate (MSNG) and three stone open fire (TFS) respectively. MSWG, showed the highest savings potential on wood fuel consumption with the lowest total wood cost of $\mathrm{N} 127.80$ and $\mathrm{sfc}$ of $1.632 \mathrm{Kg}$ of fuel $/ \mathrm{kg}$ of food cooked. While MSNG and TFS, have a total wood fuel cost and SFC of N207.70, N269.20, and 2.141, 1.632kg of fuel/kg of food cooked respectively.
\end{abstract}

Keywords: Cooking energy, efficiency, improved stove, cost, Nigeria.

\section{INTRODUCTION}

In the world today over 3 billion people still depends extensively on the utilization of conventional solid fuels to meet their daily cooking needs. Majority of these population lives in the developing countries. Specifically, China, India and the Sub-Saharan Africa. In this circumstance wood is often the only energy source for domestic (household) and small productive activities. However, this will bring about an additional pressure on the natural resources which are already heavily exploited by the industrial sector and the global wood trade, worsening the issues of desertification and deforestation [1, 2].

In Nigeria, the cooking energy demand exceeds the supply, for this reason many households have been forced by existing circumstances to change from other sources of cooking energy to the most availabe and affordable; wood [3]. However, the countrywide utilization of cooking energy is rising daily owing to the increasing population approximated at over 150 million people growing at an annual rate of $2.83 \%$ in 2008 [4]. Regrettably, the energy (petroleum products) delivered to the domestic sector has been declining over the past three decades owing to economic, social and political inequalities [3]. Nigeria has a large energy resource base. The country's oil and natural gas reserve is about 36.2 billion barrels and 184 trillion cubic feet (TCF) as at 2009 [5]. Coal and lignite reserves are estimated at 2.7 tons and tar sand reserve of 31 billion barrels of oil

*Address correspondence to this author at the Department of Mechanical Engineeering, University of Agriculture, P.M.B. 2373 Maurdi, Nigeria;

E-mail: moseskuhe74@gmail.com equivalent. The country has a good exposure to solar radiation of $3.5-7.0 \mathrm{KWh} / \mathrm{m}^{2} /$ day and an average annual wind speed of $2-4 \mathrm{~m} / \mathrm{s}$. With these abundant resources the country is still facing a serious cooking energy crisis and inefficiency in the energy utilization and conversion processes thus leading to increase cost and environmental polution.

Furthemore, The total annual consumption of fuelwood in the country in 1987 was estimated at about 80 million cubic meters. Because of the inefficiency of the local fuel-wood stoves, the bulk of the energy available from wood-burning was lost, amounting to 97 per cent [6]. In terms of the average per capita wood consumption, urban dwellers use about $360 \mathrm{~kg} /$ person, while in the rural areas the average per capita consumption has been put at $511.2 \mathrm{~kg} /$ person or 0.71 $\mathrm{m}$ of solid wood. They have been several designs of wood-burning stoves to improve performance by many researchers. Amongs these are, the Kilakala stove [7, 8] with a saving capacity of $30 \%$. The Kenya Ceramic Jiko (KCJ) stove with a use heat of about $25-40 \%$ [9], the Vented Mud stove (IVM), with average thermal efficiency of about $23.5 \%$ and the circular wood stoove by [10] with an improved efficiency of over $40 \%$ and low specific fuel consumption of 0.447 .

The objectives of this present work theefore, is (i) to improve the performance of the MNNG ( called ekwuk stove in south-eastern Nigeria) wood burning clay cookstoves used in most parts of Nigeria by the introduction of a grate, (ii) compare the performance of the improved stove with the 3-stone fire conventional stove and (iii) investigate the economic potential of the improved stove in (i). 


\section{MATERIALS AND METHODS}

\subsection{Stoves Tested}

Fuel wood is the primary source of energy for house-holds in Nigeria. Pressure in many regions has made the demand for fire wood consistently exceed the supply. There should be an alternative solution for a drastic reduction of fuel wood consumption. Cooking in Nigeria is typically performed on three stone fires (TFS). In order to identify an improved stove that decrease wood consumption and ensure faster cooking time, two different types of O-shaped clay brick cook stoves as built by users in many parts of Nigeria were tested and are discussed below. They are basically constructed with mud or clay earth blocks. To give a complete comparison on the fuel wood resources available, a TFS was also tested.

\subsubsection{Modified Stove}

The modified stove is a clay fuel wood efficient stove. It is basically an arrangement of clay earth blocks through which a tunnel runs horizontally. The fire is built beneath the cook hole. Although the Oshaped clay brick surround cook stoves enclose the wood burning chamber in a form of 'combustion chamber', they do not possess a chimney, but the cook stoves are usually constructed under open shades thereby reducing the effect of emitted particles and gases on the users.

The external diameter of the stoves is $45 \mathrm{~cm}$ diameter, with a height of $38 \mathrm{~cm}$. The clay walls guarantee a minimal insulation to the combustion chamber.

The difference between the two models is that most parts of Nigeria MSNG are fuelled with wood on the earthen base in the combustion chamber, while the MSWG is modified by introduction of grate above the earthen floor for holding the fuel wood (Figures 1, 2 and 3).

\subsection{Water Boiling and Control Cooking Tests}

The water boiling test (WBT) was started with the high-power cold start, in which the stoves under study were used to boil $1.95 \mathrm{~kg}$ of water using pre-weighed fuel (firewood). The fuel was charged into the stove and ignited and the temperature of the water in the pot was recorded with a thermometer at regular intervals of 5 minutes until the water was brought to brisk boil. The mass of the unburned wood, fuel consumed and amount of water evaporated were determined and

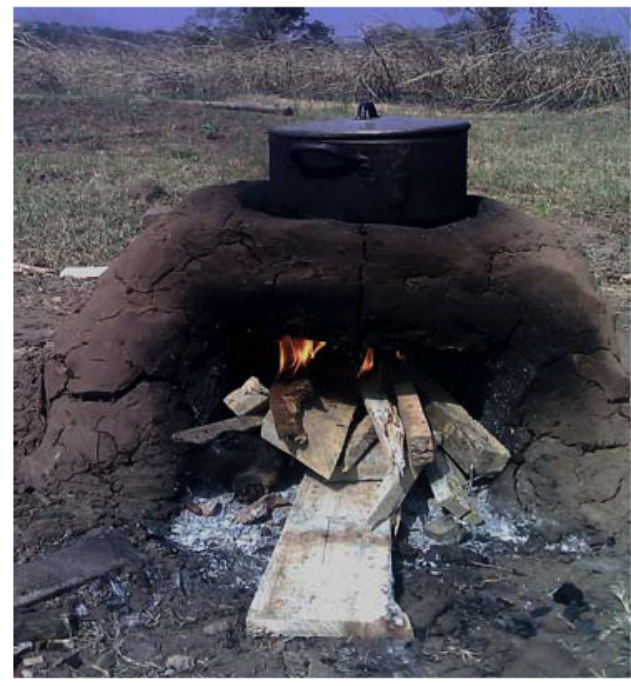

Figure 1: O-shaped clay brick stove.

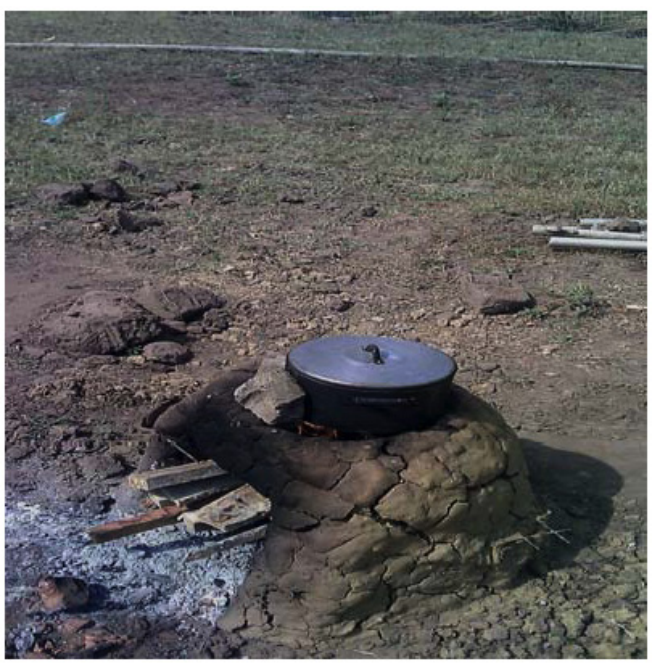

Figure 2: O-shaped clay brick stove with grate.

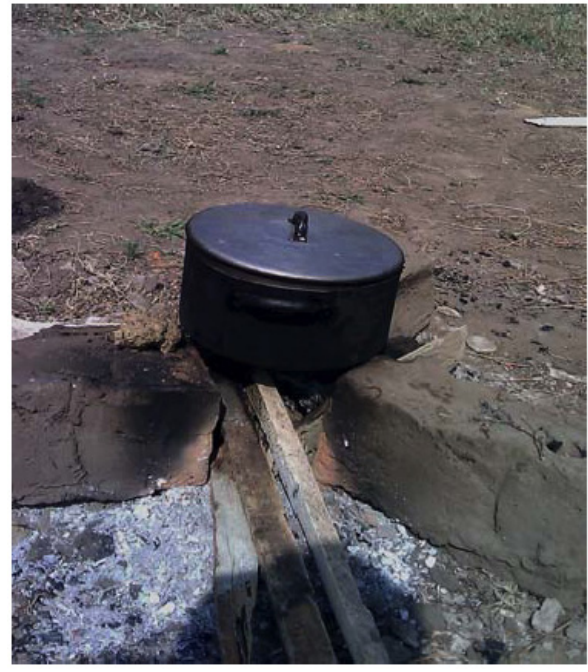

Figure 3: Three stone open fire.

recorded. The high-power hot start phase test was carried out immediately after the WBT high-power cold 
start phase (while the stove is still warm\} to determine the variation between the performance of the stoves at cold and warm state. The test procedures used for the high-power cold start phase was repeated for the hot start phase. The final test in the WBT was the lowpower simmering phase test. Here, the amount of fuel required to simmer a given quantity of water at just below boiling point was determined. The fire was adjusted to maintain the temperature of the water at just 2 to 3 degrees below the established local boiling point for about 45 minutes. Basic parameters for the two cases above were determined. Similarly, the controlled cooking test (CCT) was carried out with $0.281 \mathrm{~kg}$ of beans cooked with same ingredients in successions on the three stoves, the experiments were replicated and the averge values determined.

\subsection{Performance Parameters}

(a) The thermal efficiency for boiling water was determined using Eq. (1) below [3].

$\eta=\frac{M_{w} C_{p}\left(T_{f}-T_{i}\right)+h_{f g} M_{w v}}{M_{f w} E_{f w}} \times 100$

Where $\eta$ is the thermal efficiency (\%), $M_{w}$ is the mass of water $(\mathrm{kg}), C_{p}$ is specific heat capacity of water $(\mathrm{J} / \mathrm{kgK}), T_{f}$ is the boiling temperature, $T_{i}$ is the initial temperature of water, $M_{w v}$ is mass of water evaporated $(\mathrm{kg}), h_{f g}$ is the enthalpy of vapourization of water $(\mathrm{kJ} / \mathrm{kg}), M_{f w}$ is the weight of dry wood consumed and $E_{f w}$ is the calorific value of food fuel. For cases where the fuel wood does not burn completely to ashes, the following corresction is made as shown in equation (2) [11].

$M_{f w}=($ weight of wood burnt-weight of charcoal left)

(b) The fire power $(P)$ is the ratio of the wood energy consumed by the stove per unit time in (W) during each phase of the test as presented in equation (3) [12].

$P=\frac{M_{f w} \times E_{f w}}{60\left(T_{f}-T_{i}\right)}$

(c) The specific fuel consumption (sfc) is calculated using equation below which is the amount of fuel wood required to produce one litre of boiling water. $s f c=\frac{E_{f w}}{W_{w f}}$

Where $W_{w f}$ is the weight of water boiled. The expression of sfc in terms of quantity of the fuel wood consumed per unit mass of food cooked is expressed as in equation (5) [12].

(d)

$$
s f c=\frac{M_{f w}-\left[M_{c}\left(\frac{E_{f w}}{E_{c h}}\right)\right]}{1 \mathrm{~kg}(\text { food cooked })}
$$

Where, $M_{c}(\mathrm{~kg})$ is the mass of charcoal remaining at the end of the test and $E_{c h}$ is the calorific value of charcoal.

(e) Energy costs: The cost of thermal energy $\left(C_{t}\right)$ is calculated from the following expression,

$C_{t}=\frac{P_{F}}{M_{f w} \times E_{f w}}$

Where, $P_{F}$ is the price of fuel and the product $\left(M_{f w} \times E_{f w}\right)$ is the energy consumed

\section{RESULTS AND DISCUSSION}

Tables 1 and 2 show the water boiling parameters for MSWG, MSNG and TFS respectively for the WBT. The WBT for the cold start phase in Table 1 shows that the energy consumption for MSNG < MSWG < TSF and in the range $(7.72$ to $9.78 \mathrm{KW})$. While for the hot start and simmering phases the energy consumption for MSWG < MSNG < TSF in the range (8.17 to $9.86 \mathrm{KW}$ ) and MSWG < MSNG < TSF in the range (8.34-11.57KW) respectively.

However, MSNG utilizes wood energy at slower rate than MSWG and TFS respectively while at the hot and simmering phases MSWG has the slowest rate of energy consumption of about $8.17 \mathrm{KW}$ and $3.49 \mathrm{KW}$ with TSF having the highest rate of wood energy consumption of about 8.34 and $11.57 \mathrm{KW}$ for the two phases respectively. The thermal efficiencies of the stoves for the three phases, cold start, hot start and simmer phases in Table 3 are $19 \%, 24 \%$ and $35.9 \%$ for MSWG, $16 \%, 19.7 \%$ and $22.8 \%$ for MSNG and $11.7 \%$, $13.8 \%$ and $26.8 \%$ for TSF. The MSWG was observed to be the most efficient for all the three phases of the test except for the simmer phase, where it has the least 
Table 1: Water Boiling Test (WBT) Parameters

\begin{tabular}{|c|c|c|c|c|c|c|c|c|c|}
\hline & \multicolumn{3}{|c|}{ Cold start phase } & \multicolumn{3}{|c|}{ Hot start phase } & \multicolumn{3}{|c|}{ Simmer phase } \\
\hline & MSNG & MSWG & TSF & MSNG & MSWG & TSF & MSNG & MSWG & TSF \\
\hline Initial tempt. $\left({ }^{\circ} \mathrm{C}\right)$ & 31.60 & 32.00 & 33.10 & 32.10 & 33.00 & 32.80 & 33.10 & 33.20 & 33.30 \\
\hline Initial mass of fuel $(\mathrm{kg})$ & 3.120 & 2.590 & 3.500 & 2.520 & 2.090 & 2.800 & 2.020 & 1.690 & 2.200 \\
\hline Final mass of fuel $(\mathrm{kg})$ & 2.520 & 2.090 & 2.800 & 2.020 & 1.690 & 2.200 & 0.500 & 1.000 & 0.100 \\
\hline Initial mass of water $(\mathrm{kg})$ & 1.950 & 1.950 & 1.950 & 1.950 & 1.950 & 1.950 & 1.550 & 1.500 & 1.650 \\
\hline Mass of water evaporated (kg) & 0.410 & 0.450 & 0.300 & 0.400 & 0.450 & 0.300 & 0.150 & 0.200 & 0.150 \\
\hline Initial tempt. of water $\left({ }^{\circ} \mathrm{C}\right)$ & 30.80 & 31.00 & 30.60 & 32.6 & 33.10 & 31.9 & 97.2 & 97.4 & 97.5 \\
\hline Final tempt. of water $\left({ }^{\circ} \mathrm{C}\right)$ & 98.40 & 98.60 & 98.5 & 98.40 & 98.60 & 98.50 & 95.80 & 95.60 & 96.40 \\
\hline
\end{tabular}

Table 2: Derived Parameters from WBT

\begin{tabular}{|c|c|c|c|c|c|c|c|c|c|}
\hline & \multicolumn{3}{|c|}{ Cold start phase } & \multicolumn{3}{|c|}{ Hot start phase } & \multicolumn{3}{|c|}{ Simmer phase } \\
\hline & MSNG & MSWG & TSF & MSNG & MSWG & TSF & MSNG & MSWG & TSF \\
\hline Ebullition time (mins) & 20 & 17 & 22 & 12 & 12 & 13 & 45 & 45 & 45 \\
\hline Burning rate (g/min) & 24.55 & 25.71 & 25.45 & 32.67 & 28.42 & 36.54 & 26.53 & 11.11 & 36.82 \\
\hline Thermal efficiency & 16.00 & 19.00 & 11.70 & 19.70 & 24.40 & 13.80 & 22.80 & 35.90 & 26.80 \\
\hline Specific fuel consumption (g/L) & 227.44 & 219.19 & 225.42 & 196.01 & 167.36 & 171.77 & 385.80 & 345.00 & 366.70 \\
\hline Fire power $(\mathrm{KW})$ & 7.72 & 8.08 & 8.00 & 10.17 & 8.85 & 11.38 & 8.34 & 3.49 & 11.57 \\
\hline
\end{tabular}

Table 3: Controlled Cooking Test (CCT) Parameters

\begin{tabular}{|c|c|c|c|}
\hline CCT parameters & MSNG & MSWG & 2.650 \\
\hline \hline Initial mass of fuel $(\mathrm{kg})$ & 2.700 & 1.150 & 39 \\
\hline Final mass of fuel $(\mathrm{kg})$ & 0.850 & 42 & 2.450 \\
\hline Total time spent (mins) & 2.141 & 1.632 \\
\hline Specific fuel consumption (kg of fuel/kg of food cooked) & 0.300 & 0.113 \\
\hline Mass of charcoal recovered $(\mathrm{kg})$ & 0.091 & 0.492 \\
\hline
\end{tabular}

efficiency while the TSF has the least thermal efficiencies in all the three phases of the test. It must also be noted that the efficiency of wood cook-stooves depends on many factors which include the type and thickness of the material used in construction of the cooking port, percentage of moisture content of the wood and degree of heating [13].

The specific fuel consumptions (SFC) for the WBT and CCT senerios are presented in Figures $\mathbf{1}$ and 2. It is observed that for WBT, the MSWG (Figure 1) maintained the lowest SFC of about $219.19 \mathrm{~g} / \mathrm{L}$, $167.36 \mathrm{~g} / \mathrm{L}$ and $345 \mathrm{~g} / \mathrm{L}$ for the cold start, hot start and simer phases respectively. Simmilarly, MSWG mainted the lowest SFC of $(1.632 \mathrm{~kg}$ of fuel $/ \mathrm{kg}$ of food) for the CCT followed by MSNG.

This implies that for all conditions for which the stoves could operate, the MSWG in WBT requires the smallest amount of wood fuel to heat a liter of water to 
any given temperature. The best optimal performance of all the stoves in WBT were obtained in the hot start phase.

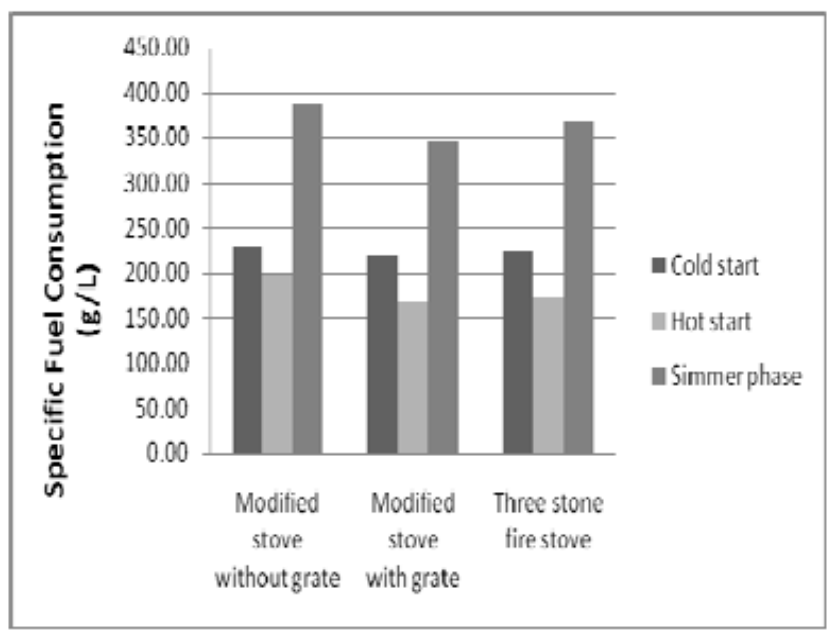

Figure 4: Specific fuel consumption of the stoves (WBT).

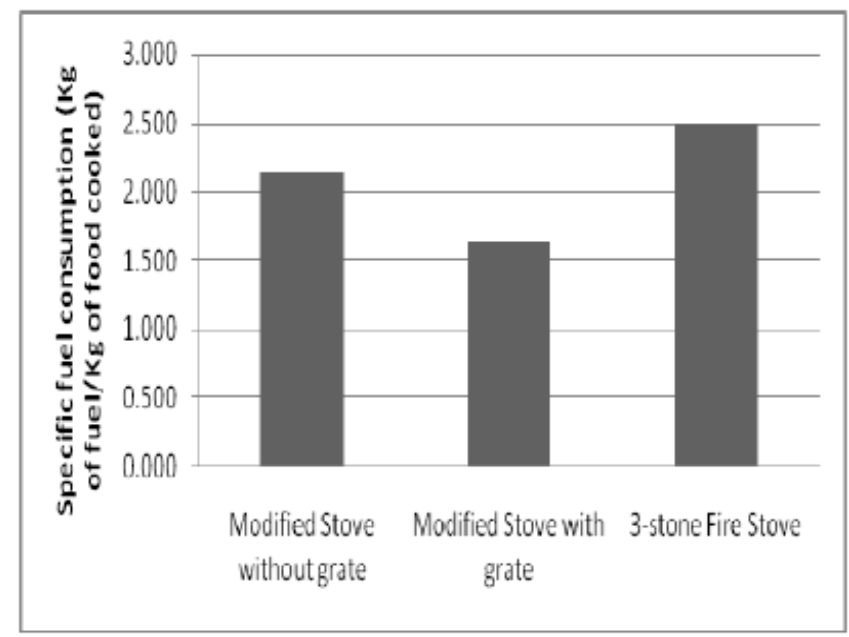

Figure 5: Specific fuel consumption of the stoves (CCT).

Figures $\mathbf{4}$ and $\mathbf{5}$ depict the graphs of temperature against time for WBT in the three stoves (MSNW, MWSG and TSF) for the cold and hot start phases respectively. From the graphs, the MSWG has the highest slope value of 3.468 for the cold start phase and 4.158 for the hot start phase. The MSNG and TSF has slope values of $3.38,4.028$ and $3.308,4.12$ respectively, for the cold and hot start phases. The values of the slope signify the extent by which the temperature of the water will increase in one minute. The values of slopes are higher in the hot start phase for all the stoves which shows that the water gets to the ebullution temperature faster in the hot start phase.
This substantiates the fact that the hotter the stove the higher the thermal performance [14].

\subsection{Economic Assessment of the Tested Cook Stoves}

From the total weight of fuel wood consumed during the CCT, using the local cost price of fuel wood of N100 per $\mathrm{Kg}$, the modified stove with grate showed the highest savings on fuel wood consumption with the lowest total wood cost of $127.80 \mathrm{~K}$ consumed. The modified stove without grate had a total fuel wood cost of $\mathrm{A} 207.70 \mathrm{~K}$ and the 3-stone fire stove had a total fuel wood cost of $\mathrm{N} 269.20 \mathrm{~K}$ consumed respectively.

\section{REFERENCES}

[1] WHO (World Health Organization). Country profile of environmental burden of disease. Geneva: Public Health and Environment. 2009.

[2] Geist HJ, Lambin EL. Proximate causes and underlying driving forces of tropical deforestation. BioScience 2002; 52: 143-50.

http://dx.doi.org/10.1641/00063568(2002)052[0143:PCAUDF]2.0.CO;2

[3] Anoziea, AN, Bakarea, AR, Sonibarea, JA, Oyebisi, OT. Evaluation of cooking energy cost, efficiency, impact on air pollution and policy in Nigeria. Energy 2007; 32: 1283-90. http://dx.doi.org/10.1016/j.energy.2006.07.004

[4] Dayo FB. Clean energy investment in Nigeria. International institute for sustainable development, 2008.

[5] Nigeria oil and gas bulletin 2009.

[6] Garba B, Bashir AM. Managing energy resources in Nigeria: Studies on energy consumption pattern in selected rural areas in Sokoto state. Nigerian J Renewable 2002.

[7] Crew E. Morogoro fuel wood stove project, women training center, Christian Council of Tanzania, Review and Recommendations, Intermidiate Technology Development Group (ITDG), Rugby, UK 1990.

[8] Otti T. Improved stoves in Tanzania, Stove Notes 6, FWD and ACTS Press, Nairobi, Kenya 1991.

[9] Kammen DM, Fayemi, KB. Energy, food preparation and health in Africa: The roles of Technology, Education, and Resource management. African Technology Forum 1992; 6: $11-4$

[10] Ayo SA. Design, construction and testing of an improved wood stove. AUJT 2009; 13: 12-8.

[11] Gerald F, Patricia M, Lloyd T. Stove and trees. London and Washintong, DC. International Institute for Environment and Development 1986.

[12] Micuta W. "Modern stoves for all", Intermediate Technology Publications (in association with) the Bellerive foundation, 1985.

[13] Bhattacharya SC, Albina DO, Khaing AM. Effect of selected parameters on performance and emmission of biomass-fired cook-stooves. Biomass Bioenergy 2002; 23: 387-95. http://dx.doi.org/10.1016/S0961-9534(02)00062-4

[14] World Bank. Household cook stoves, environment, health and climate change, 2011. 